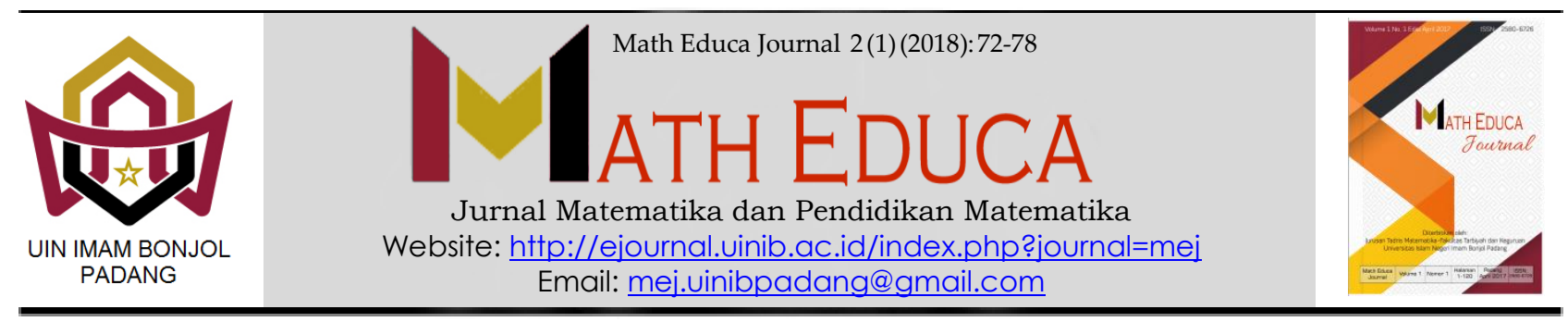

\title{
KEMAMPUAN SPASIAL MAHASISWA CALON GURU MATEMATIKA BERJENIS KELAMIN PEREMPUAN DALAM MENGKONSTRUKSI IRISAN PRISMA
}

\author{
M. Imamuddin ${ }^{1}$, Isnaniah ${ }^{2}$ \\ ${ }^{1,2}$ Pendidikan Matematika FTIK IAIN Bukittinggi \\ Email: ${ }^{1}$ m.imamuddin76@yahoo.co.id; ${ }^{2}$ iis_imam@yahoo.co.id
}

Received: January 2018; Accepted: March 2018; Published: April 2018

\begin{abstract}
Abstrak
Kemampuan mahasiswa dalam belajar matematika khususnya geometri masih menjadi perhatian dosen dan para peneliti sampai saat ini. Salah satu materi pada geometri adalah geometri ruang. Untuk dapat memahami geometri ruang dibutuhkan kemampuan spasial/keruangan yang baik dan benar. Penelitian ini bertujuan mengkaji kemampuan spasial mahasiswa calon guru matematika berjenis kelamin perempuan dalam mengkonstruksi irisan prisma. Subjek dalam penelitian ini diambil secara acak satu orang mahasiswa perempuan yang mempunyai kemampuan sedang. Hasil penelitian menyimpulkan kemampuan mahasiswa calon guru matematika berjenis kelamin perempuan dalam mengkonstruksi irisan prisma adalah: lemah dalam kemampuan persepsi keruangan (Spatial Perception), lemah dalam kemampuan relasi keruangan (Spatial relations) dan lemah dalam kemampuan visualisasi keruangan (Spatial visualisation).
\end{abstract}

Kata kunci: Kemampuan spasial, Perempuan, Mengkonstruksi, Irisan prisma.

\section{Abstract}

Nowadays, the ability of students in learning geometry is still a concern of lecturers or researchers especially for space geometry. The spatial ability is needed to understand more about space geometry. This study aims to examine the spatial ability of female pre-service mathematics teacher in constructing prism slices. Subjects in this study were taken randomly one female student who has a medium ability. The results of this study conclude that the ability of her in constructing prism slices is weak in spatial ability of perception, relations and visualisation.

Keywords: Spatial Ability, Female Student, Construct, Prism Sliced.

Peer review under responsibility UIN Imam Bonjol Padang.

(C) 2018 UIN Imam Bonjol Padang. All rights reserved.

p-ISSN: 2580-6726

e-ISSN: 2598-2133 



\section{PENDAHULUAN}

Kemampuan siswa atau mahasiswa dalam belajar matematika khususnya geometri masih menjadi perhatian guru, dosen dan para peneliti sampai saat ini. Salah satu materi pada geometri adalah geometri ruang. Geometri ruang merupakan studi tentang benda-benda ruang, relasi-relasi dan transformasi-transformasi yang telah dibentuk (dijadikan matematika) dan sistem-sistem aksioma matematika yang menjadikannya (Isnaniah, 2016).

Untuk dapat memahami geometri ruang dibutuhkan kemampuan spasial/keruangan yang baik dan benar. Hal ini sejalan dengan pendapat Soemadi yaitu agar dapat belajar geometri dengan baik dan benar, siswa dituntut untuk menguasai kemampuan dasar geometri, keterampilan dalam pembuktian, keterampilan dalam membuat lukisan dasar geometri dan mempunyai pandangan ruang yang memadai (Soemadi, 1994).

Kemampuan spasial didefinisikan sebagai kemampuan untuk membangkitkan, mempertahankan, mendapat kembali dan mengubah bayangan visual (Lohman, 1993). Kemampuan spasial menyangkut kemampuan dalam merepresentasi, mentransformasi, dan memanggil kembali informasi simbolis Linn \& Petersen (dalam Yilmaz, 2009). Sedangkan Gree's (dalam Kariadinata, 2010) mengemukakan bahwa kemampuan spasial mencangkup:

1. Spasial visualization (SV), which involves the ability to mentally manipulate, rotate, twist or iviert a pictorially presented stimulus object

2. Spasial orientation $(S R-O)$ which the comprehension of the arrangement of the elemen within visual stimulus pattern and aptitude to remain unconfused by the changing orientations in which a spatial configurations may be presented.

Sedangkan Maier (dalam Isnaniah, 2016) membagi unsur-unsur kemampuan spasial sebagai berikut:

1. Spatial Perception (persepsi keruangan)

Persepsi keruangan merupakan kemampuan mengamati suatu bangun ruang atau bagianbagian ruang yang diletakkan posisi horizontal atau vertikal.

2. Spatial visualisation (visualisasi keruangan) Visualisasi keruangan sebagai kemampuan untuk membayangkan atau membayangkan gambar tentang suatu bangun ruang yang bagian-bagian terdapat perubahan atau perpindahan.

3. Mental rotation (rotasi pikiran)

Rotasi pikiran mencakup kemampuan merotasikan suatu bangun ruang secara cepat dan tepat.

4. Spatial relations (relasi keruangan)

Kemampuan untuk mengerti wujud keruangan dari suatu benda atau bagian dari benda dan hubungannya antara bagian yang satu dengan yang lainnya.

5. Spatial orientation (orientasi keruangan)

Kemampuan untuk mencari pedoman sendiri secara fisik atau mental di dalam ruang, atau berorientasi dalam situasi keruangan yang istimewa.

Berdasarkan pendapat dan unsur-unsur kemampuan spasial di atas, maka tidak boleh tidak bagi mahasiswa yang mempelajari geometri ruang harus memiliki kemampuan spasial yang baik. Namun kenyataannya berdasarkan hasil penelitian 
(Isnaniah, 2016), diketahui kemampuan spasial/keruangan mahasiswa calon guru matematika sangat lemah.

Berdasarkan pengamatan peneliti sebagai pengampu matakuliah geometri; mahasiswa calon guru matematika dalam menyelesaikan masalah geometri ruang tidak terlepas juga dari kemampuan keruangan berdasarkan jenis kelamin. Karena berdasarkan data setiap angkatan mahasiswa calon guru matematika IAIN Bukittinggi didominasi perempuan. Sekitar 75\% sampai dengan 85\% untuk setiap tahunnya mahasiswa calon guru matematika berjenis kelamin perempuan (dokumen jurusan pendidikan matematika IAIN Bukittinggi, 2017).

Jenis kelamin atau yang lebih umum sering dikaitkan dengan perbedaan gender, gender sangat mempengaruhi dalam belajar matematika. Gender berkaitan dengan aspek psikososial dari laki-laki dan perempuan. (Krutetski, 1976) mengemukakan perbedaan antara laki-laki dan perempuan dalam belajar matematika sebagai berikut: 1. Laki-laki lebih unggul dalam penalaran, perempuan lebih unggul dalam ketepatan, ketelitian, kecermatan, dan keseksamaan berpikir. 2. Laki-laki memiliki kemampuan matematika dan mekanika yang lebih baik daripada perempuan, perbedaan ini tidak nyata pada tingkat sekolah dasar akan tetapi menjadi tampak lebih jelas pada tingkat yang lebih tinggi.

Sementara (Maccoby dan Jacklyn, 1974) mengatakan laki-laki dan perempuan mempunyai perbedaan kemampuan antara lain sebagai berikut:

1. Perempuan mempunyai kemampuan verbal lebih tinggi daripada laki-laki.
2. Laki-laki lebih unggul dalam kemampuan visual spatial (penglihatan keruangan) daripada perempuan.

3. Laki-laki lebih unggul dalam kemampuan matematika.

Menurut (Susento, 2006) perbedaan gender bukan hanya berakibat pada perbedaan kemampuan dalam matematika, tetapi cara memperoleh pengetahuan matematika juga terkait dengan perbedaan gender.

Dalam penelitian ini akan mengkaji kemampuan spasial mahasiswa calon guru matematika berjenis kelamin perempuan dalam mengkonstruksi irisan prisma. Mahasiswa calon guru matematika diberikan permasalahan geometri khususnya menggambarkan irisan prisma. Irisan prisma merupakan salah satu sub bab dari materi bangun ruang. Bangun ruang merupakan salah satu materi atau bab yang terdapat dalam matakuliah geometri bidang dan ruang. Matakuliah ini, diberikan kepada mahasiswa calon guru matematika IAIN Bukittinggi di semester 2 (dua).

\section{METODE PENELITIAN}

Berikut ini diuraikan tentang jenis penelitian, waktu dan tempat penelitian, populasi dan sampel, prosedur, instrumen serta teknik analisis data.

\section{Jenis Penelitian}

Penelitian ini termasuk dalam penelitian kualitatif. Penelitian ini akan mengkaji kemampuan spasial mahasiswa calon guru matematika perempuan dengan kemampuan sedang dalam mengkonstruksi irisan prisma. 


\section{Waktu dan Tempat Penelitian}

Penelitian ini dilaksanakan pada semester II Tahun Akademik 2016/2017 kepada mahasiswa calon guru matematika IAIN Bukittinggi.

\section{Target/Subjek Penelitian/Populasi dan Sampel}

Subjek penelitian ini adalah mahasiswa calon guru Matematika IAIN Bukittinggi yang telah menempuh mata kuliah geometri bidang dan ruang. Subjek penelitian ditentukan dengan cara acak terhadap satu orang mahasiswa perempuan berkemampuan sedang dan selanjutnya disebut subjek S.

\section{Prosedur}

Penelitian ini dilakukan dengan cara memberikan Lembar Tugas Mahasiswa (LTM) kepada subjek S. Lembar Tugas Mahasiswa (LTM) berisikan satu soal yang terkait irisan prisma. Dari jawaban yang diperoleh pada LTM selanjutnya dilakukan wawancara yang mendalam dengan subjek S.

\section{Data, Intrumen, dan Teknik Pengumpulan Data}

Data dalam penelitian ini, diperoleh langsung dari subjek penelitian (subjek S). Instrumen utama dalam penelitian ini adalah peneliti sendiri. Sedangkan Instrumen tambahan yang digunakan dalam penelitian ini adalah Lembar Tugas Mahasiswa (LTM) yang berisi satu soal tentang irisan prisma. Fungsi peneliti sebagai pengumpul data pada penelitian ini tidak bisa digantikan oleh orang lain.

Pengumpulan data dilakukan dengan cara memberikan Lembar Tugas Mahasiswa (LTM) kepada mahasiswa calon guru matematika yang berisi soal irisan prisma. Setelah diperoleh jawaban dari subjek $\mathrm{S}$, selanjutnya dilakukan wawancara yang mendalam dengan subjek $\mathrm{S}$ terkait jawaban yang telah diberikan.

\section{Teknik Analisis Data}

Berdasarkan jawaban subjek S terhadap soal yang terdapat pada LTM, selanjutnya subjek S diwawancarai secara mendalam untuk menjelaskan langkah-langkah atau tahapan-tahapan pengerjan terhadap jawaban yang sudah diberikan. Dari jawaban yang diberikan terhadap soal pada LTM dan penjelasan subjek $\mathrm{S}$ ketika diwawancarai selanjutnya dilakukan analisis dengan cara mencari kesamaan untuk kemudian dibuat kesimpulannya.

\section{HASIL PENELITIAN DAN PEMBAHASAN}

Permasalahan yang diberikan kepada subjek S, seperti yang dijelaskan pada metode penelitian adalah sebagai berikut:

Kubus ABCD.EFGH dengan panjang rusuk 6 satuan, sudut surut $60^{\circ}$, perbandingan proyeksi 2 : 1 dan sebagai bidang frontal CDHG. Pada kubus tersebut terdapat titik P, Q dan R. Titik P terletak pada rusuk $\mathrm{CG}(\mathrm{P}=2 / 6 \overline{C G})$, titik $\mathrm{Q}$ terletak pada rusuk $\mathrm{DH}(\mathrm{Q}=1 / 6 \overline{\mathrm{DH}})$, dan titik $\mathrm{R}$ terletak pada rusuk $\mathrm{AE}(\mathrm{R}=4 / 6 \overline{A E})$. Gambarlah irisan prisma ABCD.EFGH yang melalui titik $P, Q$ dan $R$ dengan menggunakan cara sumbu afinitas.

Sedangkan salah satu jawaban atau gambar dari penyelesain permasalahan yang diberikan dapat dilihat pada Gambar 1

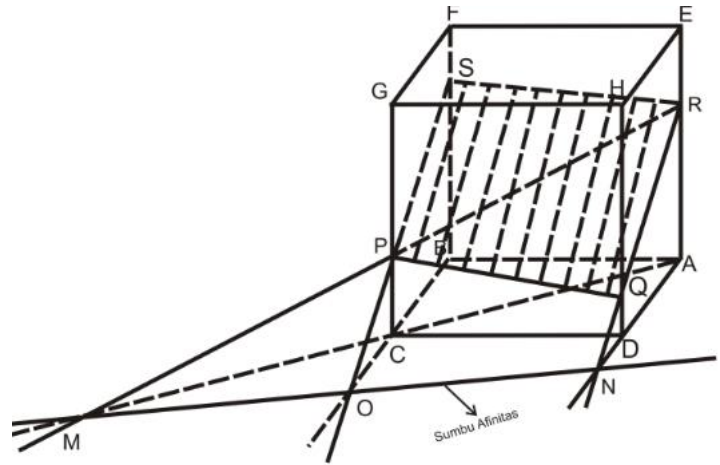

Gambar 1.Gambar Irisan Prisma dari Permasalahan 
Irisan prisma PQRS yang terbentuk diselesaikan dengan langkah-langkah mengambar/penyelesaian sebagai berikut:

1. Buat (perpanjang) garis $\mathrm{AD}$ dan garis $\mathrm{RQ}$ pada bidang sisi tegak DAEH, yang berpotongan di titik $\mathrm{N}$.

2. Buat (perpanjang) garis $\mathrm{AC}$ dan garis $\mathrm{RP}$ pada bidang diagonal ACGE, yang berpotongan di titik $\mathrm{M}$.

3. Buat garis NM, garis NM merupakan sumbu affinitas.

4. Buat (perpanjang) garis $\mathrm{BC}$, garis $\mathrm{BC}$ memotong (sumbu afinitas) NM di titik O.

5. Titik $\mathrm{O}$ dan $\mathrm{P}$ dihubungkan, terbentuk garis OP yang memotong rusuk BF di titik $\mathrm{S}$.

6. Hubungkan $\mathrm{P}$ dengan $\mathrm{Q}$ dan $\mathrm{R}$ dengan $\mathrm{S}$.

7. Segiempat PQRS adalah irisan prisma dengan bidang yang melalui titik-titik $\mathrm{P}, \mathrm{Q}$ dan R.

Sedangkan hasil jawaban tertulis yang telah dibuat di LTM dan penjelasan lisan yang diperoleh melalui wawancara dengan subjek $\mathrm{S}$, ditranskrip dalam bentuk paparan data subjek S. Jawaban subjek S terhadap soal pada LTM dapat dilihat pada Gambar 2.

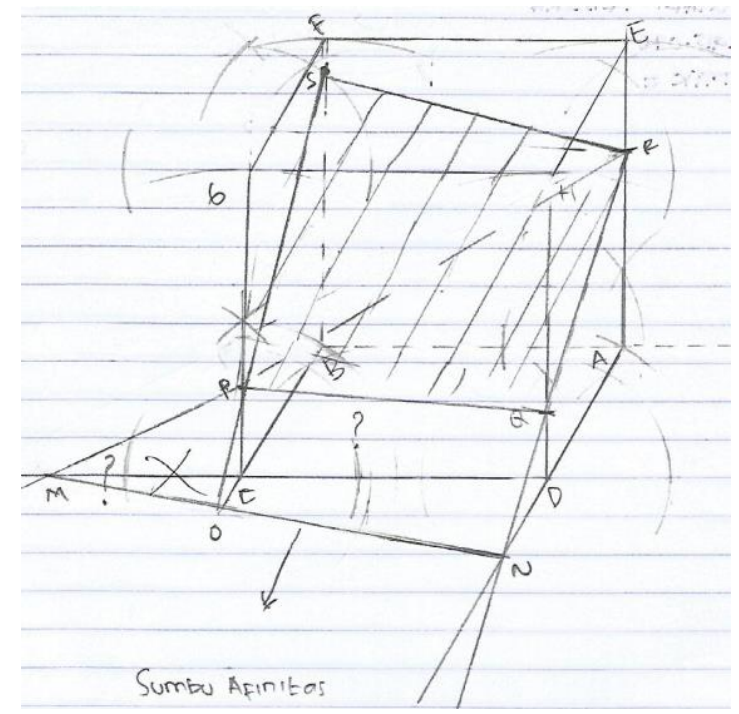

Gambar 2. Hasil Kerja Subjek S
Berdasarkan jawaban subjek S pada LTK dan wawancara yang mendalam diperoleh data/informasi sebagai berikut; jawaban subjek $\mathrm{S}$ terhadap LTM, yang pada gambar terlihat tidak menghubungkan titik $\mathrm{A}$ dan $\mathrm{C}$ (tidak membuat garis AC). Dari wawancara dengan subjek $\mathrm{S}$ diperoleh informasi, subjek $\mathrm{S}$ kurang atau tidak memperhatikan garis/segmen/bagian-bagian yang terletak pada bagian posisi horizontal pada prisma ABCD.EFGH. Hal ini dikarenakan subjek S lemah dalam kemampuan persepsi keruangan (Spatial Perception).

Selain itu subjek $\mathrm{S}$ membuat garis $\mathrm{RP}$ berpotongan dengan perpanjangan garis DC di titik M. Seharusnya Subjek S membuat garis AC dan membuat garis RP sehingga berpotongan di titik M. Berdasarkan wawancara dengan subjek $\mathrm{S}$ di peroleh informasi, subjek $S$ hanya memperhatikan hasil kerjanya pada LTM yang menghasilkan garis RP dan DC berpotongan di titik M. Subjek S tidak menyadari bahwa garis RP dan garis DC terletak pada bidang yang berbeda, garis RP terletak pada bidang diagonal CAEG dan garis DC terletak pada bidang frontal CDHG. Sehingga perpanjang garis RP dan garis DC tidak akan pernah berpotongan. Subjek S kurang memahami bahwa dua garis akan berpotongan apabila terletak pada bidang yang sama. Subjek S kurang paham terhadap bagianbagian dari bangun ruang dan hubungannya antara bagian yang satu dengan yang lainnya. Hal ini menandakan atau menunjukkan subjek $\mathrm{S}$ masih lemah dalam kemampuan relasi keruangan (Spatial relations).

Disamping itu, dalam membuat garis CB, PS dan RS, subjek $\mathrm{S}$ dalam gambarnya membuat garis CB, PS dan RS tidak putus-putus. Seharusnya 
segmen $\mathrm{CB}$, PS dan RS dibuat putus-putus menandakan letak segmen PS dan RS berada dibagian yang tidak terlihat dari depan. Berdasarkan wawancara dengan subjek S, hal ini disebabkan karena subjek $\mathrm{S}$ kurang dalam kemampuan membayangkan gambar tentang letak atu bagian-bagian dari bangun ruang. Hal ini menunjukkan subjek $\mathrm{S}$ masih lemah dalam kemampuan visualisasi keruangan (Spatial visualisation).

Pendidik (dosen/guru) dapat meminimalkan kelaman-kelemahan kemampuan spasial/keruangan mahasiswa/siswa dalam menyelesaikan permasalahan geometri ruang (bangun ruang) dengan cara sering memberikan latihan terkait bangun ruang. Hal ini sejalan dengan yang dikemukakan oleh Lohman (dalam McNulty, 2007) yang mengemukakan bahwa perbedaan gender dalam kemampuan spasial ini bisa dieliminasi dengan latihan.

\section{SIMPULAN DAN SARAN}

\section{Simpulan}

Berdasarkan analisis data dan pembahasan diperoleh kesimpulan bahwa kemampuan mahasiswa calon guru matematika berjenis kelamin perempuan dalam merekonstruksi irisan prisma adalah; lemah dalam kemampuan persepsi keruangan (Spatial Perception), lemah dalam kemampuan relasi keruangan (Spatial relations) dan lemah dalam kemampuan visualisasi keruangan (Spatial visualisation).

\section{Saran}

Berdasarkan hasil penelitian ini, disarankan beberapa hal kepada pengajar matematika sebagai berikut.

1. Dalam pembelajaran di kelas atau pembimbingan mahasiswa di luar kelas hendaknya dosen memperhatikan mahasiswa ditinjau berdasarkan gender.

2. Memperhatikan bagaimana mahasiswa perempuan mengkonstruksi irisan prisma ini dapat dijadikan pijakan ketika dosen mengajarkan materi tersebut di kelas.

3. Hasil penelitian ini dapat dijadikan informasi awal untuk membuat penelitian yang lebih luas tentang bagaimana mahasiswa mengkonstruksi suatu konsep matematika.

\section{REFERENSI}

Isnaniah. (2016). Analisis Spasial Abilities Mahasiswa Program Studi Pendidikan Matematika STAIN Bukittinggi. Jurnal Penelitian dan Kajian Ilmiah Menara Ilmu, Vol X Jilid 1 No. 64 Februari 2016. ISSN 1693-2617 Hal. 89-103 LPPM UMSB.

Kariadinata, Rahayu dkk, (2010). Kemampuan Visualisasi Geometri Spasial Siswa Madrasah Aliyah Negeri (MAN) Kelas X Melalui Software Pembelajaran Mandiri. PPPPTK Matematika

Krutetski, V.A. (1976). The Psychology of Mathematics Abilities in school children. Chicago: The University of Chicago press.

Lohman, D. F. (1993). Spatial Ability and G. Paper presented at the First Spearman Seminar, University of Plymouth.

Maccoby, E.E \& Jacklin, C.N. (1974). The Psychology of Sex Differences. Stanford: Stanford University 
McNulty, Kathleen P. (2007). Gender Differences in Spatial Abilities: A Meta-Analysis. Senior Thesis : Psychology of Georgia Institute of Technology. Scholarly Materials and Research at Tech.

Soemadi, (1994). Pengajaran Geometri Di Sekolah-Sekolah Indonesia (Satuan Pemikiran Alternatif). FMIPA: IKIP Surabaya
Susento. (2006). Mekanisme Interaksi Antara Pengalaman Kultural-Matematis, Proses Kognitif, dan Topangan dalam Reivensi Terbimbing. Disertasi. Surabaya: Unesa.

Yilmaz, H.B. (2009). On The Development and Measurement of Spatial Ability. International Electronic Journal of Elementary Education. Vol.1 No.2. 